\title{
EXPERIENCE WITH THE USE OF PIOGLITAZONE FOR THE PREVENTION AND TREATMENT OF EXPERIMENTAL URATE NEPHROLITHIASIS
}

Department of pharmacology, Altai State Medical University, Barnaul, Russia

\section{РЕФЕРАТ}

ЦЕЛЬ. Оценить эффективность селективного агониста PPAR гамма-рецепторов (Peroxisome Proliferator-Activated Receptor) пиоглитазона в качестве средства профилактики и лечения экспериментальной уратной нефропатии. МАТЕРИАЛ И МЕТОДЫ. Работа проведена на 37 крысах-самцах линии Вистар. Для формирования уратной нефропатии у крыс ингибировали уриказу путем совместного введения мочевой и оксониевой кислот. Для профилактики и лечения экспериментальной патологии животные получали пиоглитазон. На 21 сутки с помощью биохимических и морфологических методов оценивали полученные изменения. РЕЗУЛЬТАТЫ. В условиях экспериментальной терапии наблюдалось достоверное снижение количества уратных камней в почках, значительное уменьшение уровня мочевой кислоты в плазме крови и моче крыс, повышение рН мочи, рост скорости клубочковой фильтрации и угнетение процессов свободно-радикального окисления в крови животных. ЗАКЛЮЧЕНИЕ. Длительное применение пиоглитазона в профилактическом и лечебном режимах существенно облегчает течение экспериментального уратного нефролитиаза.

Ключевые слова: пиоглитазон, экспериментальный уратный нефролитиаз, профилактика, лечение.

\section{ABSTRACT}

THE AIM. To assess the effectiveness of selective agonist of PPAR gamma receptors (Peroxisome Proliferator-Activated Receptor) pioglitazone, as a drug of prevention and treatment of experimental urate nephropathy. MATERIAL AND METHODS. The study was conducted on 37 male rats Wistar stock. For the formation of urate nephropathy in rats inhibited uricase by co-administration of uric acid and oxonium. For the prevention and treatment of experimental pathology animals received pioglitazone. On day 21 using biochemical and morphological techniques were evaluated received changes. RESULTS. In the experimental condition were observed significant decrease of urate stones in kidneys, significant decrease of uric acid in blood plasma and urine of rats, increase of the urine $\mathrm{pH}$, increase of glomerular filtration rate and inhibition processes of free radical oxidation in the blood of animals. CONCLUSION. Long-term use of pioglitazone in the preventive and therapeutic modes, significantly improves the experimental urate nephrolithiasis.

Key words: pioglitazone, experimental urate nephrolithiasis, prevention, treatment.

\section{ВВЕДЕНИЕ}

Четвертая часть населения современных развитых стран страдают метаболическим синдромом (MC) $[1,2]$. У таких пациентов, наряду с признаками МС, включающими в себя абдоминальное ожирение, дислипидемию, нарушение толерантности к глюкозе, а также гипертензию, часто отмечаются нарушения метаболизма пуринов, по-

Перфильев В.Ю. 656038, Россия, г. Барнаул, пр. Ленина, д. 40 Алтайский государственный медицинский университет, кафедра фармакологии. Тел.: +7 (3852) 24-18-59, +7 (923) 566-52-45. E-mail: 1991PS@mail.ru. дагра и мочекислый нефролитиаз [3, 4]. Так, в РФ распространенность метаболического синдрома у лиц, страдающих подагрой, составляет, в среднем, $57 \%$, а уратного нефролитиаза у пациентов с MC достигает $21,9 \%[5,6]$. Попытки определить общие звенья патогенеза этих состояний позволили выявить повышенную кислотность мочи, которая вызвана нарушением образования и почечного транспорта аммония [7-9]. Результаты проведенных с этой целью исследований показывают, что чрезмерная ацидификация мочи обусловлена, главным образом, инсулинорезистентностью [10, 
11]. Мы предположили, что применение препарата, способного повысить чувствительность тканей к инсулину, может привести к уменьшению проявлений уратной нефропатии. В качестве такого препарата было выбрано синтетическое противодиабетическое средство, производное тиозалидиндиона - «пиоглитазон».

Цель данного исследования - оценить эффективность селективного агониста PPAR гаммарецепторов (Peroxisome Proliferator-Activated Receptor) пиоглитазона в качестве средства профилактики и лечения экспериментальной уратной нефропатии.

\section{МАТЕРИАЛ И МЕТОДЫ}

Работа проведена на 37 крысах-самцах линии Вистар массой 200-250 г. Животные находились в индивидуальных клетках, приспособленных для сбора мочи. Условия содержания соответствовали требованиям Европейской конвенции по защите позвоночных животных, используемых для экспериментальных и иных научных целей (г. Страсбург, 1986).

Для формирования уратной нефропатии у крыс использовали воспроизведенную нами ранее модель ингибирования уриказы, вызывающую развитие гиперурикемии у грызунов [12]. Животных разделили на 3 группы: 17 контрольных животных и по 10 животных в каждой опытной группе. Контрольная группа в качестве диеты в течение 3 нед ежедневно свободно потребляла по 20 г стандартной лабораторной смеси, содержавшей 0,145 г оксониевой кислоты $(\mathrm{OK})$ и 0,3 г мочевой кислоты (МК). Вторая группа (группа «Профилактика») в профилактическом режиме на протяжении такого же периода времени дополнительно получала внутрь пиоглитазон в дозе 2,2 мг/кг. Животным из третьей группы (группа «Лечение») вводили пиоглитазон в той же дозе с 11-го по 21-й день эксперимента.

В суточной моче животных определяли содержание МК, общего белка, креатинина и активность ферментов-маркеров дисфункции почек: лактатдегидрогеназы (ЛДГ), гамма-глутамилтрансферазы (ГГТ) и $\mathrm{N}$-ацетил- $\beta$-D-глюкозаминидазы (НАГ). По окончании эксперимента в крови крыс, полученной после декапитации, определяли содержание МК, креатинина, активность каталазы (КАТ), глутатионпероксидазы (ГПО), супероксиддисмутазы (СОД), восстановленного глутатиона (ВГ), тиобарбитурат-реактивных продуктов (ТБРП), общую антиоксидантную активность (OAA) и общую прооксидантную активность (ОПА). В поч- ках крыс определяли те же параметры свободнорадикального окисления (СРО) и подсчитывали количество уратных микролитов в просвете канальцев на срезах, окрашенных гематоксилином и эозином при стократном увеличении.

Для проведения статистического анализа данных использовали пакеты прикладных статистических программ «Microsoft Office Excel 2003» («Microsoft Corporation», США) и «Sigma-Stat 3.5» («Systat Software Inc.», США). Полученные данные приведены в виде средняя арифметическая \pm ошибка средней. Для сравнения данных использовали однофакторный дисперсионный анализ (ANOVA), различия считали статистически значимыми при $\mathrm{p}<0,05$. Для проведения апостериорных попарных сравнений применяли критерий наименьшей значимой разности (Fisher LSD), различия считали статистически значимыми при $\mathrm{p}<0,0253$.

\section{РЕЗУЛЬТАТЫ}

В табл. 1 приведены показатели содержания мочевой кислоты и функции почек у крыс с экспериментальным уратным нефролитиазом при введении пиоглитазона в профилактическом и лечебном режимах. Введение пиоглитазона животным в обеих группах сопровождалось снижением концентрации МК в плазме экспериментальных животных по сравнению с контрольной группой на $21,4 \%$ в группе «Профилактика» и на $35,7 \%$ в группе «Лечение», что закономерно повлекло за собой снижение экскреции МК с мочой в 3,9 раза в группе «Профилактика» и в 3 раза в группе «Лечение».

Учитывая важность изменения $\mathrm{pH}$ в патогенезе уратного нефролитиаза, необходимо отметить, что применение пиоглитазона в профилактическом режиме (см. табл. 1) привело к существенному сдвигу этого показателя (на $11,1 \%$ ) в щелочную сторону по сравнению с контролем. В группе животных, которые получали препарат в режиме лечения, также проявилась тенденция к ощелачиванию мочи, не достигавшая, однако, статистической значимости.

Кроме того, нами были зафиксированы признаки снижения тяжести течения уратной нефропатии. Так, оба режима введения пиоглитазона сопровождались увеличением СКФ в экспериментальных группах и более выраженным у крыс, получавших препарат в режиме «Лечение» (см. табл. 1). Косвенным свидетельством благоприятного влияния пиоглитазона на состояние почечного эпителия служит также тенденция к снижению 
Показатели содержания мочевой кислоты и функции почек у крыс

\section{с экспериментальным уратным нефролитиазом при введении пиоглитазона в профилактическом и лечебном режимах}

\begin{tabular}{|c|c|c|c|c|c|c|}
\hline \multirow[b]{2}{*}{ Группа } & \multirow[b]{2}{*}{$\mathrm{n}$} & \multicolumn{2}{|l|}{ Мочевая кислота } & \multirow[b]{2}{*}{ СКФ, мл/мин } & \multirow[b]{2}{*}{ рН мочи, ед } & \multirow[b]{2}{*}{ Активность ЛДГ, U/л } \\
\hline & & $\begin{array}{l}\text { Концентрация в плаз- } \\
\text { ме, мг/дл }\end{array}$ & Экскреция с мочой, мг & & & \\
\hline Контроль («К») & 17 & $1,4 \pm 0,09$ & $28,5 \pm 1,70$ & $18,0 \pm 1,25$ & $7,2 \pm 0,21$ & $1,2 \pm 0,17$ \\
\hline Лечение («Л») & 10 & $1,1 \pm 0,05$ & $7,3 \pm 0,65$ & $21,6 \pm 2,30$ & $8,0 \pm 0,19$ & $1,0 \pm 0,17$ \\
\hline Профилактика («П») & 10 & $0,9 \pm 0,08$ & $9,5 \pm 1,20$ & $25,0 \pm 2,21$ & $7,6 \pm 0,20$ & $1,0 \pm 0,14$ \\
\hline \multicolumn{7}{|c|}{ Статистическая значимость различий (критерий PLSD Фишера, ANOVA) } \\
\hline $\mathrm{p}, \ll K » и \ll \Pi »$ & & 0,013 & $<0,001$ & НД & 0,009 & НД \\
\hline $\mathrm{p}, \ll$ И «Л» & & $<0,001$ & $<0,001$ & 0,006 & НД & НД \\
\hline $\mathrm{p}, \ll \Pi » и \ll Л »$ & & НД & НД & НД & НД & НД \\
\hline
\end{tabular}

Примечание. Зесь и в табл. 2: n - число животных; p - уровень статистической значимости различий; НД - различия статистически незначимы.

\section{Показатели активности свободно-радикального окисления в крови крыс с экспериментальным уратным нефролитиазом при введении пиоглитазона в профилактическом и лечебном режимах}

\begin{tabular}{|c|c|c|c|c|c|c|c|}
\hline \multirow{2}{*}{ Группа } & \multirow{2}{*}{$n$} & \multirow{2}{*}{ ОПА, \% } & \multirow{2}{*}{ ТБРП, мкМ } & \multirow{2}{*}{ OAA, $\%$} & \multicolumn{3}{|c|}{ Антиоксидантные ферменты } \\
\hline & & & & & KAT, \% & ГПО, \% & СОД, \% \\
\hline Контроль («К») & 17 & $73,4 \pm 4,00$ & $4,8 \pm 0,19$ & $36,7 \pm 1,92$ & $0,6 \pm 0,02$ & $14,1 \pm 0,58$ & $18,4 \pm 1,72$ \\
\hline Лечение («Л») & 10 & $41,1 \pm 1,48$ & $3,8 \pm 0,15$ & $30,7 \pm 1,01$ & $0,7 \pm 0,03$ & $13,8 \pm 0,15$ & $16,9 \pm 0,42$ \\
\hline Профилактика («П») & 10 & $52,6 \pm 0,75$ & $3,5 \pm 0,21$ & $35,8 \pm 0,90$ & $0,7 \pm 0,03$ & $14,4 \pm 0,24$ & $16,6 \pm 0,42$ \\
\hline \multicolumn{8}{|c|}{ Статистическая значимость различий (критерий PLSD Фишера, ANOVA) } \\
\hline $\mathrm{p}, \ll K » и \ll \Pi »$ & & $<0,001$ & $<0,001$ & 0,015 & НД & НД & НД \\
\hline $\mathrm{p}, \ll K » и \ll Л »$ & & $<0,001$ & $<0,001$ & НД & НД & НД & НД \\
\hline p, «П» и «Л» & & 0,021 & НД & НД & НД & НД & НД \\
\hline
\end{tabular}

уровня ЛДГ в моче крыс в обеих экспериментальных группах. Активность ГГТ и НАГ в моче существенно не изменялись.

Как видно из табл. 2, в результате проведенных экспериментов было зафиксировано значительное снижение общей прооксидантной активности плазмы в обеих экспериментальных группах по сравнению с контрольными значениями. Концентрация ТБРП в плазме крови животных из групп «Профилактика» и «Лечение» также была статистически значимо ниже таковой в контрольной группе в 1,3 и 1,4 раза соответственно. Данные изменения фиксировали на фоне значительного повышения ОАА в почках животных, которые получали пиоглитазон в профилактическом режиме по сравнению с контрольной группой. В группе «Лечение» имелась лишь тенденция к увеличению ОАА в почках. Описанные изменения закономерно повлекли за собой достоверное повышение уровня ВГ в почках: контрольная группа $2,1 \pm 0,18 \%$, группа «Профилактика» - 3,0土0,16\%

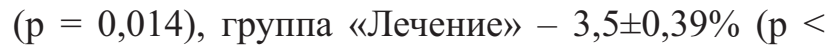
0,001). Интересно, что на этом фоне активность антиоксидантных ферментов в обеих эксперимен- тальных группах не отличалась от контрольных значений.

Благоприятное действие пиоглитазона на течение экспериментального нефролитиаза подтвердилось в результате подсчета уратных микролитов в гистологических срезах почек. В обеих опытных группах наблюдали значительное уменьшение числа мочекислых камней по сравнению с контрольной группой, причем в большей степени снижение их образования наблюдалось в группе животных, получавших пиоглитазон в лечебном режиме. Если в контрольной группе количество микролитов в просвете почечных канальцев составило $19,6 \pm 3,67$, то в группе «Профилактика» этот показатель снизился до 9,3 $\pm 2,35$ ( $\mathrm{p}=0,016)$, а в группе «Лечение» - до 2,0土0,89 (p <0,001).

\section{ОБСУЖДЕНИЕ}

Полученные результаты свидетельствуют о том, что пиоглитазон участвует не только в метаболизме углеводов и липидов, но и пуринов, что закономерно приводит к уменьшению количества уратных микролитов в почках, снижению концентрации МК в плазме и ее экскреции с мочой. 
Как отмечалось выше, важную роль в ацидификации мочи играет инсулинорезистентность. Установлено, что инсулин, активируя инсулиновые рецепторы в почечных канальцах, стимулирует активность изоформы $3 \mathrm{Na}^{+} / \mathrm{H}^{+}$-обменника, который обеспечивает как перенос через мембрану ионов водорода для последующего взаимодействия с $\mathrm{NH}_{3}$, так и прямой транспорт $\mathrm{NH}_{3}$ в просвет канальца [13]. Кроме того, известно, что инсулин активирует метаболизм глутамина через глутамат и $\alpha$-кетоглутарат, в результате чего образуется аммиак в клетках проксимальных почечных канальцев [14]. Таким образом, инсулинорезистентность приводит к снижению образования и секреции аммония, что и способствует ацидификации мочи. Мы предполагаем, что пиоглитазон, повышая чувствительность инсулиновых рецепторов почечных канальцев к инсулину, активирует функцию изоформы $3 \mathrm{Na}^{+} /$ $\mathrm{H}^{+}$-обменника и, как следствие, транспорт $\mathrm{NH}_{3}$ в просвет почечного канальца, что и приводит к повышению $\mathrm{pH}$ мочи.

Выяснено, что важную роль в патогенезе уратной нефропатии играет активация процессов СРО. Этому способствуют свободные радикалы, которые генерируются в процессе окисления гипоксантина в ксантин, а ксантина - в МК. Эти процессы катализируют ферменты ксантиноксидоредуктаза и ксантиноксидаза, которые и способствуют образованию активных форм кислорода [15]. Кроме того, установлено, что в условиях гиперурикемии в ходе окисления МК образуется уратный радикал, обладающий прямой прооксидантной активностью [16]. Поэтому особый интерес вызвало положительное влияние пиоглитазона на процессы СРО, сопровождающие течение экспериментальной уратной патологии. Вместе с тем, отсутствие изменения активности антиоксидантных ферментов на фоне его приема свидетельствует о том, что снижение процессов СРО в данном случае, по-видимому, обеспечивается активацией неферментной линии антиоксидантной защиты, которая включает в себя низкомолекулярные соединения, обладающие антиоксидантным свойством [14]. Следует отметить, что в низких концентрациях МК сама способна проявлять антиоксидантные свойства, действуя как скавенджер свободных радикалов и хелатор ионов переходных металлов, которые превращаются в слабореактивные формы [16-18]. Не исключено, что пиоглитазон, снижая концентрацию МК в плазме и моче, способствует проявлению ее антиоксидантных свойств.

\section{ЗАКЛЮЧЕНИЕ}

Длительное применение пиоглитазона в профилактическом и лечебном режимах существенно облегчает течение экспериментального уратного нефролитиаза, что подтверждается достоверным снижением количества уратных камней в почках, значительным уменьшением уровня мочевой кислоты в плазме крови и моче крыс, повышением рН мочи, ростом СКФ и угнетением процесса свободно-радикального окисления в крови животных.

\section{БИБЛИОГРАФИЧЕСКИЙ СПИСОК}

1. Калашникова МФ. Метаболический синдром: современный взгляд на концепцию, методы профилактики и лечения. Эффективная фармакотерапия 2013; 52: 52-63 [Kalashnikova MF. Metabolicheskij sindrom: sovremennyj vzgljad na koncepciju, metody profilaktiki i lechenija. Jeffektivnaja farmakoterapija. 2013; 52: 52-63]

2. Kim Y-J, Kim C-H, Sung E-J et al. Association of nephrolithiasis with metabolic syndrome and its components. Metabolism 2013; 62 (6): 808-813

3. Антипова ВН, Казеева МВ. Кардиоваскулярный риск и метаболический синдром у больных подагрой. Изв высших учебных заведений. Поволжский регион. Мед науки 2015; 1 (33): 112-122 [Antipova VN, Kazeeva MV. Kardiovaskuljarnyj risk i metabolicheskij sindrom u bol'nyh podagroj. Izvestija vysshih uchebnyh zavedenij. Povolzhskij region. Medicinskie nauki 2015; 1 (33): 112-122]

4. Бокарев ИН. Метаболический синдром. Клин мед 2014; 92 (8): 71-76 [Bokarev IN. Metabolicheskij sindrom. Klinicheskaja medicina 2014; 92 (8): 71-76]

5. Барскова ВГ, Елисеев МС, Денисов ИС и др. Частота метаболического синдрома и сопутствующих заболеваний у больных подагрой. Данные многоцентрового исследования Науч-практ ревматол 2012; 50 (6): 15-18 [Barskova VG, Eliseev MS, Denisov IS i dr. Chastota metabolicheskogo sindroma i soputstvujushhih zabolevanij u bol'nyh podagroj. Dannye mnogocentrovogo issledovanija Nauchno-prakticheskaja revmatologija. 2012; 50 (6): 15-18]

6. Akman T, Binbay M, Erbin A et al. The impact of metabolic syndrome on long-term outcomes of percutaneous nephrolithotomy (PCNL). BJU Int 2012; 110: E1079-E1083

7. Bobulescu IA, Maalouf NM, Capolongo G et al. Renal ammonium excretion after an acute acid load: blunted response in uric acid stone formers but not in patients with type 2 diabetes. Am J Physiol Renal Physiol 2013; 305: E1498-E1503

8. Daskalopoulou SS, Mikhailidis DP, Elisaf M. Prevention and treatment of the metabolic syndrome. Angiology 2004; 55 (6): 3145-3152

9. Sakhaee K, Maalouf NM. Metabolic syndrome and uric acid nephrolithiasis. Semin Nephrol 2008; 28 (2): 174-180

10. Abate N, Chandalia M, Cabo-Chan AV Jr et al. The metabolic syndrome and uric acid nephrolithiasis: novel features of renal manifestation of insulin resistance. Kidney Int 2004; 65: 386-392

11. Cameron MA, Maalouf NM, Adams-Huet B et al. Urine composition in type 2 diabetes: predisposition to uric acid nephrolithiasis. J Am Soc Nephrol 2006; 17: 1422-1428

12. Перфильев ВЮ, Зверев ЯФ, Брюханов ВМ и др. Успешный опыт моделирования уратной нефропатии у крыс. Нефрология 2016; 4 (20): 93-97 [Perfil'ev VJu, Zverev JaF, Brjuhanov VM i dr. Uspeshnyj opyt modelirovanija uratnoj nefropatii u krys. Nefrologija 2016; 4 (20): 93-97]

13. Curthoys NP. Renal ammonium ion production and excretion. In: Alpern RJ, Caplan M, Moe OW eds. Seldin and Giebisch's The Kidney Physiology and Pathophysiology (5th ed.). San Diego, CA: Academic Press, 2013; 1995-2019 
14. Nissim I, States B, Nissim I et al. Hormonal regulation of glutamine metabolism by OK cells. Kidney Int 1995; (47) 96-105

15. Schulz E, Gori T, Münzel T. Oxidative stress and endothelial dysfunction in hypertension. Hypertens Res 2011; 34: 665-673

16. Glantzounis GK, Tsimoyiannis EC, Kappas AM et al. Uric acid and oxidative stress. Curr Pharm Des 2005; 32, 11: 4145-4151

17. Титов ВН, Дмитриев ВА, Гущина ОВ и др. Физикохимическая активность мочевой кислоты. Гиперурикемия - нарушение биологических функций эндоэкологии и адаптации, биологических реакций экскреции, воспаления и гидродинамического артериального давления. Успехи совр биол 2011; 131 (5): 483-502 [Titov VN, Dmitriev VA, Gushhina OV i dr. Fiziko-himicheskaja aktivnost' mochevoj kisloty. Giperurikemija - narushenie biologicheskih funkcij jendojekologii i adaptacii, biologicheskih reakcij jekskrecii, vospalenija i gidrodinamicheskogo arterial'nogo davlenija. Uspehi sovr biol 2011; 131 (5): 483-502]

18. Parman M.S. Uric acid and cardiovascular risk. N Engl J Med 2009; 360: 539

\section{Сведения об авторах:}

Перфильев Вячеслав Юрьевич

656038, Россия, г. Барнаул, пр. Ленина, д. 40. Алтайский государственный медицинский университет, кафедра фармакологии. Тел.: +7 (3852) 24-18-59, +7 (923) 566-52-45. E-mail 1991PS@mail.ru

Perfilev Y. Vyacheslav

Affiliations: 656038, Russia, Barnaul, Lenin Avenue 40, Altai State Medical University, Department of Pharmacology. Phone: +7 (3852) 24-18-59, +7 (923) 566-52-45, E-mail 1991PS@mail.ru

Проф. Зверев Яков Федорович, д.м.н.

656038, Россия, г. Барнаул, пр. Ленина, д. 40. Алтайский государственный медицинский университет, кафедра фармакологии. Тел.: +7 (3852) 24-18-68

Prof. Yakov F. Zverev DMedSci.

Affiliations: 656038, Russia, Barnaul, Lenin Avenue 40, the Altai
State Medical University, Department of Pharmacology. Phone: +7 (3852) 24-18-68, E-mail zver@asmu.ru.

Проф. Жариков Александр Юрьевич, д.б.н.

656038, Россия, г. Барнаул, пр. Ленина, д. 40. Алтайский государственный медицинский университет, кафедра фармакологии. Тел.: +7 (3852) 24-18-68, e-mail: zharikov@agmu.ru

Prof. Alexander Yu. Zharikov DBiolSci

Affiliations: 656038, Russia, Barnaul, Lenin Avenue 40, the Altai State Medical University, Department of Pharmacology. Phone: +7 (3852) 24-18-68, E-mail: zharikov@agmu.ru.

Лукьяненко Д.Ю.

Студент V курса медико-профилактического факультета, e-mail: 1991PS@mail.ru

Lukyanenko D.Yu.

5th year students of medical - prophylactic faculty, e-mail: 1991PS@mail.ru

Лысенко И.В.

Студент VI курса лечебного факультета, e-mail: 1991PS@mail.ru Lysenko I.V.

6th year students of medical faculty, e-mail: 1991PS@mail.ru

Атабаева Ольга Шукурулловна, к.б.н.

доцент кафедры фармакологии, e-mail: oatabaeva@mail.ru.

Atabaeva O.Sh. CBiolSci

Affiliations: 656038, Russia, Barnaul, Lenin Avenue 40, the Altai State Medical University, Department of Pharmacology. Phone: +7 (3852) 24-18-68, e-mail: oatabaeva@mail.ru.

Авторы заявляют об отсутствии конфликта интересов. 